\title{
The effect of XBRL adoption on information symmetry in companies' financial reports through knowledge management: Perceptions of employees of the Jordan securities commission
}

\author{
Tareq O. Bani-Khalid ${ }^{a^{*}}$, Abdelrahman K. El-Dalabeeh ${ }^{\mathrm{b}}$ and Abdullah M Al-Adamat
}

\begin{abstract}
${ }^{a}$ Associate Professor of Financial Accounting; Department of Accounting; Faculty of Economics \& Administrative Sciences; Al al-Bayt University; P.O.Box 130040, Mafraq 25113, Jordan

${ }^{b}$ Associate Professor of Accounting Information System; Faculty of Economics \& Administrative Sciences- Al al-Bayt University; P.O.Box 130040, Mafraq 25113, Jordan 'Associate Professor of Business Management; Department of Business Administration; Faculty of Economics \& Administrative Sciences; Al al-Bayt University; P.O.Box 130040, Mafraq 25113, Jordan

C H R O N I C L E

\begin{tabular}{l}
\hline Article history: \\
Received: October 28, 2020 \\
Received in revised format: \\
November 282020 \\
Accepted: December 22, 2020 \\
Available online: \\
December 22, 2020 \\
\hline Keywords: \\
XBRL \\
Information symmetry \\
Knowledge management \\
Securities Commission \\
Jordan
\end{tabular}

A B S T R A C T

The aim of this study is to investigate the impact of XBRL adoption on information symmetry in the presence of knowledge management as a mediating variable. Data were collected using a questionnaire distributed to all employees working at the Jordan Securities Commission (JSC). Applying the partial least squares method via SmartPLS-3, the results pointed out that the XBRL had significant positive direct effects on knowledge management and information symmetry, knowledge management had a significant positive direct effect on information symmetry. Hence, a partially mediating significant effect of knowledge management was detected between the XBRL and information symmetry. Accordingly, the study recommended governmental legislative bodies to continue supporting XBRL adoption to improve the quality of financial information. The study also recommends understanding the perceptions of preparers and users of financial statements about challenges that hinder the adoption of XBRL in various commercial sectors in order to improve the consistency of informational content in annual reports.
\end{abstract}

\section{Introduction}

On the ground of its vital advantages, many institutions all over the world have widely adopted the eXtensible Business Reporting Language (XBRL) standard for financial and business reporting. The U.S. Securities and Exchange Commission (SEC) mandated all listed companies in 2009 to disclose their financial information using XBRL format (Blankespoor, Miller \& White, 2014). In China, the Ministry of Finance called companies in 2012 for using accounting systems that are able to produce financial reports in XBRL (Wang, Chen \& Xu, 2017). In India, the XBRL was adopted by the Reserve Bank of India (RBI) (Kumar, Kumar and Dilip, 2019). Many other countries adopted the XBRL. In terms of the effects of XBRL adoption on information asymmetry, findings reported in the literature indicated that the adoption of XBRL results in reduced levels of information asymmetry (Chong et al., 2017; Liu, Luo \& Wang, 2017; Yoon, Zo \& Ciganek, 2011). On the other hand, some studies found no effect of XBRL on information asymmetry. Examining the effect of XBRL on information asymmetry using data from Indonesian companies, Tohang, Limijaya and Chitrahadi (2020) found no significant effect of XBRL on information asymmetry. Zamroni and Aryani (2018) indicated that XBRL had no important implications to financial information in the Indonesian stock market. The impact of the XBRL standard can be investigated considering its effect on information transparency, information asymmetry, forecasting accuracy, cost of capital, and financial comparability (Awad, 2018). Challenges of accounting knowledge management in the digital era can be

* Corresponding author. Tel: +96226297000

E-mail address: tareq_alkhaldi@aabu.edu.jo (T. O. Bani-Khalid) 
faced with the integration of innovative financial technologies like XBRL, artificial intelligence, cryptocurrencies, and Blockchain (Mosteanu \& Faccia, 2020). Wang, Chen and Xu (2017) added that analyzing financial reports on the web such as those disclosed using XBRL has regarded as a key challenge in knowledge management. Bai, Sakaue and Takeda (2014) reported an important part of XBRL adoption in the enhancement of information environment in Japan. For Blankespoor, Miller and White (2014), XBRL changes data communication and processing, since it enables collecting and analyzing more data. Therefore, it was concluded that knowledge management would induce significant effects on the role played the XBRL to enhance information asymmetry.

For the current study, the aim is to investigate the effect of XBRL adoption on information symmetry in the presence of knowledge management as a mediating variable using a sample of employees at the Jordanian Securities Commission (JSC).

\section{Literature review and hypotheses development}

\section{$2.1 X B R L$}

XBRL has been defined as an international standard used by companies for the purpose of storing, manipulating, and communicating business and financial reports in a timely, accurate, and efficient manner (Bergeron, 2003). It is an application of Extensible Markup Language (XML) (Gray \& Miller, 2009). For Blankespoor, Miller and White (2014), XBRL refers to a business reporting electronic language that assists companies in conducting automated processes like information acquisition, classification, representation and comparing. XBRL is a digital format of business and financial reports used instead of traditional reports written in PDF or HTML format (Ahmi \& Nasir, 2019).

\subsection{Knowledge management}

Knowledge management has been defined in terms of knowledge creation, management of knowledge flow inside the firm, and the effective and efficient use of that knowledge. It had also defined as acquiring and using external and internal knowledge to achieve the organizational objectives (Ode \& Ayavoo, 2020). Knowledge management as an important mechanism used by organizations to convert its resources into capabilities has been described by knowledge acquisition, knowledge dissemination, and responsiveness to knowledge (Darroch, 2005). According to Darroch (2003), such dimensions could be measured using indicators such as availability of a relevance reporting system, sensitivity to information, disseminating of market knowledge, using communication technologies, and responding to knowledge about other parties.

\subsection{Information asymmetry}

Information asymmetry indicates that one party has private information that another party does not (Yoon, Zo \& Ciganek, 2011 in Liu, Luo \& Wang, 2017). Agency theory assumes a separation between ownership and control, which result in information asymmetry (Cohen and Holder-Webb, 2006). The agency relationship contains the principal who employs the agent to do some actions for a reward, which means that the principal delegates the agent the authority of decision making to carry out those actions. In the event that the agent does not act in the interest of the director, the problem of the agency arises, the main symptom of which is information asymmetry (Boučková, 2015; Wiseman, Cuevas-Rodríguez and Gomez-Mejia, 2012).

\subsection{Hypotheses development}

Numerous prior works showed significant benefits due to the adoption of the XBRL standard. On the ground of a sample consisted of 554 US bank loan contracts, Chong et al. (2017) outlined a significant role of the XBRL in reducing information asymmetry. Providing evidence from European non-financial firms, Liu, Luo and Wang (2017) indicated that XBRL adoption resulted in increasing market liquidity and reducing information asymmetry. Yoon, Zo and Ciganek (2011), in their study on the Korean market, revealed a positive association between the adoption of XBRL and information asymmetry. Summarizing the findings on XBRL adoption, Awad (2018) concluded that one of the most important positive effects of adopting business language is to reduce information asymmetry. Consequently, it was expected that the adoption of the XBRL would show a significant effect on information symmetry (IS) as postulated in the following hypothesis:

\section{$\mathbf{H}_{1}$ : XBRL adoption exerts a significant positive direct effect on information symmetry.}

Gao and Huang (2020) suggested that modern information technology leads to a wider information dissemination, which in turn enhance information production. Blankespoor, deHaan and Marinovic (2020) emphasized the costs of information awareness, acquisition, and integration. Chen and Zhou (2019) provided evidence on the positive role played by XBRL in improving information acquisition. Based on data collected via interviews with stakeholders to evaluate the diffusion of XBRL in Australia, Troshani and Doolin (2007) indicated that XBRL enhances communication flows and information sharing. A key feature of XBRL is that it allows the exchange of business and financial information (Hao, Zhang and Fang, 2014). In fact, no studies were found 
in the literature on the effect of XBRL on knowledge management processes. In order to fill such a gap, the following hypothesis was presumed:

\section{$\mathbf{H}_{2}$ : XBRL adoption exerts a significant positive direct effect on $K M$.}

Providing a conceptual framework of the role of knowledge management in reducing information asymmetry in online markets, Arbi, Kausar and Salim (2017) concluded that knowledge management is very important mechanism for minimizing information asymmetry in online business. In one study on information asymmetry and sharing, Clarkson, Jacobsen and Batcheller (2007) defined information asymmetry as a lack of informational awareness of one party as compared to another party and indicated that the main source of information asymmetry is insufficient information sharing. Gathering data from 307 international companies in China, Hsieh, Lai and Shi (2006) pointed out that a firm with a strong orientation in terms of its ability to access, process, capture, and use information could enhance its performance and minimize information asymmetry. The authors added that information orientation reduces information asymmetry through information sharing. Kumar and Kumar (2011) described KM as "delivering the right knowledge to the right persons at the right time" (P.114). It is understood from this that the lack of sound knowledge leads to a lack of similarity between the sender and the receiver. In order to investigate the effect of KM on information asymmetry as well as the mediating role of KM between XBRL adoption and information asymmetry, the following hypotheses were introduced:

$\mathbf{H}_{3}$ : KM exerts a significant positive direct effect on information symmetry.

$\mathbf{H}_{4}$ : XBRL adoption exerts a significant positive indirect effect on information symmetry through KM.

\section{Research method}

\subsection{Research sample and data collection}

One-hundred and twenty employees who are working at the Jordan Securities Commission (JSC) comprised the population of the study. Due to the small size of the study, a comprehensive survey was conducted for all members of the study population. Hence, 120 questionnaires were distributed to the members of the sample. Out of the distributed questionnaires, 105 responses were returned, from which 4 responses were excluded.

\subsection{Measures}

XBRL was measured using 14 items (XBRL1-XBRL14) based on related works (Gray and Miller, 2009; Blankespoor, Miller and White, 2014; Ahmi and Nasir, 2019; Liu, Luo and Wang, 2017; Yoon, Zo and Ciganek, 2011). Following Darroch (2003), knowledge management was measured using knowledge acquisition, dissemination and responsiveness to knowledge. Seven items (KM1-KM7) were developed to assess the three dimensions. Ten items were used to measure information symmetry (INF-SYS1-INF-SYS10). They were developed based on previous studies (Liu, Luo and Wang, 2017; Cohen and Holder-Webb, 2006; Boučková, 2015; Wiseman, Cuevas-Rodríguez and Gomez-Mejia, 2012; Tohang, Limijaya and Chitrahadi, 2020).

\subsection{Research model}

Fig. 1 shows the conceptual model of the study. It contains three latent variables, which are the independent variable (XBRL adoption), the mediating variable (knowledge management), and the dependent one (information symmetry).

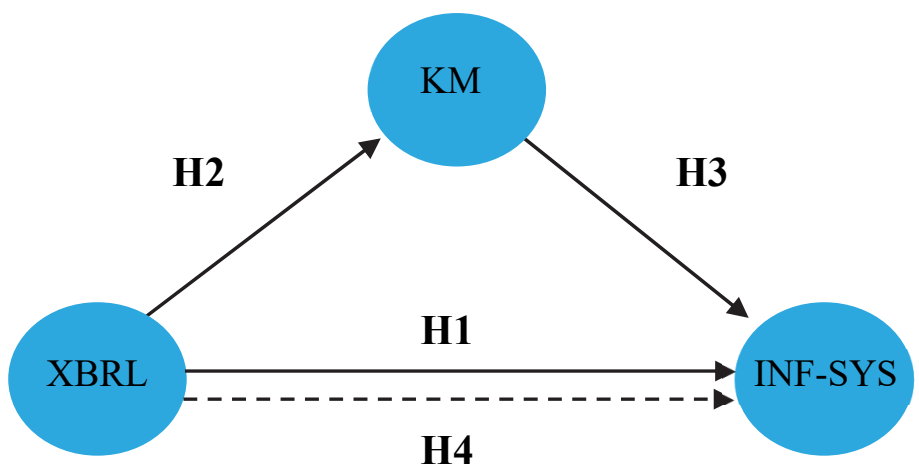

Fig. 1. Research conceptual model

\section{Empirical results and discussion}

\subsection{Validity and reliability}

Composite reliability (CR) was used to evaluate reliability, while items' factors loadings and the average variance extracted (AVE) were used to assess convergent validity and the Heterotrait-Monotrait ratio (HTMT) was used to evaluate discriminant validity (Henseler et 
al., 2015; Matthews et al., 2016). The cut-off value of CR is 0.70 or higher and the cut-off value for both factor loadings and AVEs is 0.50 (Bani-Khalid and Al-Adamat, 2020; Al-shbiel and El-Dalabeeh, 2020). The results, as shown in Table 1, indicate that all factor loadings of the independent variable (XBRL) are greater than 0.50 ranging between 0.686 and 0.859 . Similarly, all factor loadings of knowledge management are higher than 0.50 with a maximum value of 0.804 and minimum value of 0.708 . Finally, all factor loadings of information symmetry are between 0.630 and 0.796 . In terms of AVE values, it was pointed out that all XBRL adoption, KM and information symmetry had acceptable values, i.e., 0.558, 0.561, and 0.586, respectively. Additionally, the value of HTMT between XBRL and both knowledge management and information symmetry were 0.714 and 0.762 , and between knowledge management and information symmetry was 0.740 , which less than 0.90 (Henseler et al., 2015; Choi \& Chiu, 2017). Hence, validity and reliability were supported. Reliability, on the other hand, as assessed by composite reliability was found acceptable since its values were 0.924 for XBRL adoption, 0.899 for knowledge management, and 0.952 for information asymmetry. Regarding VIF (variance inflation factor), the results outlined that the current data are free of multi-collinearity problem since values of VIF were less than 10 (Helm, Eggert and Garnefeld, 2010). Moreover, the results showed that the value of Goodness of Fit (GoF) index is 0.436, which a good model fit since it is greater than 0.36 (Hussain, Konar and Ali, 2016; Quazza, Noureddine \& Zoubir, 2018). $\mathrm{R}^{2}$, as a measure of the predictive accuracy of the model, represented an acceptable accuracy of the current model (Hair et al., 2014).

Table 1

Results of validity and reliability

\begin{tabular}{|c|c|c|c|c|c|c|c|c|c|}
\hline Variable & Items & $\begin{array}{l}\text { Factor } \\
\text { loadings }\end{array}$ & AVE & $\mathbf{C R}$ & Variable & Items & $\begin{array}{l}\text { Factor } \\
\text { loadings }\end{array}$ & AVE & $\mathbf{C R}$ \\
\hline \multirow{14}{*}{ XBRL adoption } & XBRL1 & 0.830 & \multirow{14}{*}{0.558} & \multirow{14}{*}{0.924} & \multirow{21}{*}{$\begin{array}{l}\text { Information } \\
\text { symmetry }\end{array}$} & INF-SYS & 0.779 & \multirow{10}{*}{0.586} & \multirow{10}{*}{0.952} \\
\hline & XBRL2 & 0.812 & & & & INF-SYS & 0.745 & & \\
\hline & XBRL3 & 0.813 & & & & INF-SYS & 0.694 & & \\
\hline & XBRL4 & 0.831 & & & & INF-SYS & 0.720 & & \\
\hline & XBRL5 & 0.859 & & & & INF-SYS & 0.630 & & \\
\hline & XBRL6 & 0.758 & & & & INF-SYS & 0.771 & & \\
\hline & XBRL 7 & 0.804 & & & & INF-SYS & 0.728 & & \\
\hline & XBRL8 & 0.739 & & & & INF-SYS & 0.733 & & \\
\hline & XBRL9 & 0.694 & & & & INF-SYS & 0.796 & & \\
\hline & XBRL10 & 0.732 & & & & INF-SYS & 0.791 & & \\
\hline & XBRL11 & 0.686 & & & & & & & \\
\hline & XBRL12 & 0.721 & & & & & & & \\
\hline & XBRL13 & 0.705 & & & & & & & \\
\hline & XBRL14 & 0.704 & & & & & & & \\
\hline \multirow{7}{*}{$\begin{array}{l}\text { Knowledge } \\
\text { management }\end{array}$} & KM1 & 0.708 & \multirow{7}{*}{0.561} & \multirow{7}{*}{0.899} & & & & & \\
\hline & KM2 & 0.768 & & & & & & & \\
\hline & KM3 & 0.728 & & & & & & & \\
\hline & KM4 & 0.651 & & & & & & & \\
\hline & KM5 & 0.771 & & & & & & & \\
\hline & KM6 & 0.804 & & & & & & & \\
\hline & KM7 & 0.801 & & & & & & & \\
\hline
\end{tabular}

$\mathrm{R}$ square for $\mathrm{KM}=.0456$ and $\mathrm{R}$ square for $\mathrm{INF}-\mathrm{SYS}=0.556$

Goodness of Fit $(\mathrm{GoF})$ index $=0.436$

\subsection{Hypotheses testing}

The structural model of the study, as shown in Fig. 2, links three latent variables using SmartPLS 3.0 to test the hypotheses of the research.

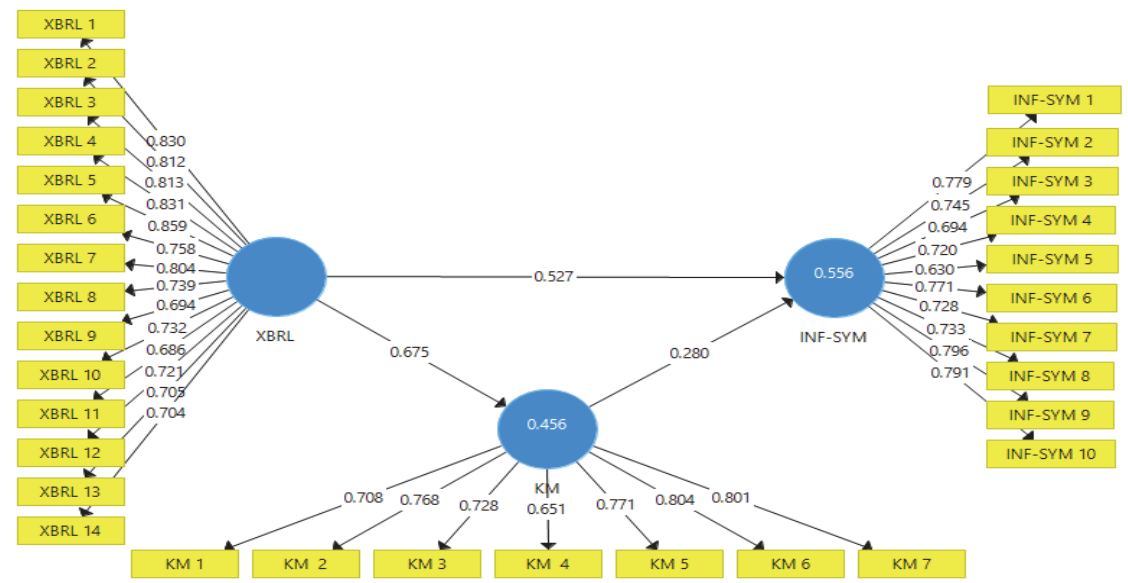

Fig. 2. Research structural model 
The results of the structural model are reported in Table 2. The results showed that XBRL had a significant positive direct effect on information symmetry (INF-SYS) $(\beta=0.716, t=4.151, \mathrm{P}=0.000)$. These results supported $\mathrm{H}_{1}$ and $\mathrm{H}_{2}$. On the other hand, the results revealed a significant direct effect of XBRL on knowledge management $(\beta=0.675, t=8.333, P=0.000)$. Moreover, the results pointed out a significant effect of knowledge management on information symmetry $(\beta=0.280, t=3.648, P=0.000)$. Finally, it was found that XBRL has a significant positive indirect effect of XBRL on information symmetry through knowledge management $(\beta=0.189, \mathrm{t}=$ $3.529, \mathrm{P}=0.000)$.

Table 2

Results of hypothesis testing

\begin{tabular}{|c|c|c|c|c|c|c|c|c|c|c|c|}
\hline & \multirow{2}{*}{\multicolumn{2}{|c|}{ Paths }} & \multicolumn{3}{|c|}{ Total effects } & \multicolumn{3}{|c|}{ Direct effects } & \multicolumn{3}{|c|}{ Indirect effects } \\
\hline & & & $\beta$ & $\mathbf{t}$ & $\mathbf{P}$ & $\beta$ & $t$ & $\mathbf{P}$ & $\beta$ & $\mathbf{t}$ & $\mathbf{P}$ \\
\hline XBRL & $\rightarrow$ & INF-SYS & 0.716 & 4.151 & 0.000 & 0.527 & 7.591 & 0.000 & 0.189 & 3.529 & 0.000 \\
\hline XBRL & $\rightarrow$ & KM & 0.675 & 8.333 & 0.000 & 0.675 & 8.333 & 0.000 & - & - & - \\
\hline KM & $\rightarrow$ & INF-SYS & 0.280 & 3.648 & 0.000 & 0.280 & 3.648 & 0.000 & - & - & - \\
\hline
\end{tabular}

The aforementioned results confirm the acceptance of the study hypotheses using the current data. The test of the first hypothesis showed a positive direct effect of XBRL on information symmetry and this is in agreement with Chong et al. (2017) who indicated that the XBRL has a significant role in minimizing information asymmetry. Similar results were also found (Liu, Luo \& Wang, 2017; Yoon, Zo and Ciganek (2011). The results of the second hypothesis indicated that the XBRL had a significant positive direct effect on KM. Parallel with this result, previous studies showed a significant role played by XBRL in enhancing information acquisition (Chen and Zhou, 2019) as well as improves communication flows and information sharing (Troshani \& Doolin, 2007). Additionally, the XBRL helps financial reporting (Hao et al., 2014). Furthermore, the results supported the hypothesis that knowledge management shows a significant direct effect on information symmetry. Hsieh, Lai and Shi (2006) found a similar result about the association between firms' strong orientation toward information access, process, capture, and use with information asymmetry reduction. According to them, a low level of information sharing minimizes information asymmetry. For Kumar and Kumar (2011), availability of the right knowledge at the right time to the right persons reduces information asymmetry. Based on these results, knowledge management played a mediating role between the XBRL and information symmetry as stated in the fourth hypothesis.

\section{Conclusion}

This study has aimed at investigating the effect of XBRL on information symmetry through knowledge management, and found that the XBRL exerts significant direct and indirect positive effects on information symmetry, which means that there is a partially mediating role played in the relationship between the XRBL and information symmetry. Therefore, it was concluded that enhancing information symmetry is achieved through XBRL effective knowledge management, particularly in the areas of knowledge sharing, dissemination, and response to knowledge. Firms are requested to adopt the XBRL due to its effective part in improving communication flows and information sharing, particularly, business and financial information. Such as adoption should consider the availability of a relevance reporting system, using communication technologies, sensitivity to information, disseminating of market knowledge, and responding to knowledge about other parties.

\section{Limitations and future research}

This study is limited to a small sample size selected from one institution, using a cross-sectional design in Jordan. Therefore, results generalization is limited to these constraints. Future studies are required to use larger samples of a larger size, and from other countries. The study also recommends conducting further studies to explore factors affecting the adoption of the XBRL from as perceived by auditors, preparers and users of financial statements from various commercial sectors. The current study tested the mediating effect of knowledge management while adopting the XBRL to improve the level of symmetry of informational content of financial reports. Using other variables, such as the effect information intensity on improving the level of symmetry of informational content, will be useful in future studies. Finally, the study recommends Jordanian governmental decision-makers and legislative bodies to continue their support for the adopting (XBRL) due to its benefits in improving the structure and content of financial and accounting reporting for listed or non-listed companies, in order to attract successful investments.

\section{References}

Ahmi, A., \& Nasir, M. H. M. (2019). Examining the trend of the research on eXtensible Business Reporting Language (XBRL): A bibliometric. International Journal of Innovation, Creativity and Change, 5(2), 11451167.

Alshbiel, S. O., \& El-Dalabeeh, A. K. (2020). The mediating effect of organizational culture on the relationship between the lean accounting and sustainable competitive advantage in Jordan. International Journal of Scientific \& Technology Research, 9(2), $2909-2916$.

Arbi, K. A., Kausar, A. R., \& Salim, I. (2017). Minimizing asymmetric information in online markets through knowledge management. International Journal of Management Excellence, 8(2), 924-931.

Awad, I. H. (2018). Evaluating the quality of IFRS information obtained from XBRL/IFRS taxonomy, with a case study (Doctoral dissertation, Tanta University). 
Bai, Z., M. Sakaue, \& Takeda, F. (2014). The impact of XBRL adoption on the information environment: Evidence from Japan. The Japanese Accounting Review, 4, 49-74.

Bergeron, B. (2003). Essentials of XBRL: Financial reporting in the 21st century. New Jersey: Wiley \& Sons, Inc.

Blankespoor, E., Miller, B. P., \& White, H. D. (2014). Initial evidence on the market impact of the XBRL mandate. Review of Accounting Studies, 19(4), 1468-1503.

Boučková, M. (2015). Management accounting and agency theory. Procedia Economics and Finance, 25, 5-13.

Chen, G., \& Zhou, J. (2019). XBRL adoption and systematic information acquisition via EDGAR. Journal of Information Systems, 33(2), 2343.

Choi, H., \& Chiu, W. (2017). Influence of the perceived organizational support, job satisfaction, and career commitment on football referees' turnover intention. Journal of Physical Education and Sport, 17, 955-959.

Chong, D., Shi, H., Fu, L., Ji, H., \& Yan, G. (2017). The impact of XBRL on information asymmetry: Evidence from loan contracting. Journal of Management Analytics, 4(2), 145-158.

Clarkson, G., Jacobsen, T. E. and Batcheller, A. L. (2007). Information asymmetry and information sharing. Government Information Quarterly, 24(4), 827-839.

Cohen, J. R., \& Holder-Webb, L. L. (2006). Rethinking the influence of agency theory in the accounting academy. Issues in Accounting Education, 21(1), 17-30.

Darroch, J. (2003). Developing a measure of knowledge management behaviours and practices. Journal of Knowledge Management, 7(5), 4154.

Darroch, J. (2005). Knowledge management, innovation and firm performance. Journal of Knowledge Management, 9(3), $101-115$.

Gao, M., \& Huang, J. (2020). Informing the market: The effect of modern information technologies on information production. The Review of Financial Studies, 33(4), 1367-1411.

Gray, G. L., \& Miller, D. W. (2009). XBRL: Solving real-world problems. International Journal of Disclosure and Governance, 6(3), $207-223$.

Hair Jr, J. F., Sarstedt, M., Hopkins, L., \& Kuppelwieser, V. G. (2014). Partial least squares structural equation modeling (PLS-SEM). European Business Review, 26(2), 106-121.

Hao, L., Zhang, J. H., \& Fang, J. B. (2014). Does voluntary adoption of XBRL reduce cost of equity capital? International Journal of Accounting and Information Management, 22(2), 86-102.

Helm, S., Eggert, A., \& Garnefeld, I. (2010). Modeling the Impact of Corporate Reputation on Customer Satisfaction and Loyalty Using Partial Least Squares. In V. Vinzi, W. Chin, J. Henseler \& H. Wang (2010). Handbook of partial least squares: Concepts, methods, and applications. (pp. 515-534). Springer-Verlag Berlin Heidelberg.

Henseler, J., Ringle, C.M., \& Sarstedt, M. (2015). A new criterion for assessing discriminant validity in variance-based structural equation modeling. Journal of the Academy of Marketing Science, 43(1), 115-135.

Hsieh, C. T., Lai, F., \& Shi, W. (2006). Information orientation and its impacts on information asymmetry and e-business adoption. Industrial Management \& Data Systems, 106(6), 825-840.

Hussain, K., Konar, R., \& Ali, F. (2016). Measuring service innovation performance through team culture and knowledge sharing behaviour in hotel services: a PLS approach. Procedia-Social and Behavioral Sciences, 224(15), 35-43.

Kumar, P., Kumar, S. S., \& Dilip, A. (2019). Effectiveness of the adoption of the XBRL standard in the Indian banking sector. Journal of Central Banking Theory and Practice, 8(1), 39-52.

Kumar, S. A., \& Kumar, T. A. (2011). Study the impact of requirements management characteristics in global software development projects: An ontology based approach. International Journal of Software Engineering \& Applications, 2(4), 107-125.

Liu, C., Luo, X. R., \& Wang, F. L. (2017). An empirical investigation on the impact of XBRL adoption on information asymmetry: Evidence from Europe. Decision Support Systems, 93, 42-50.

Matthews, L. M., Sarstedt, M., Hair, J. F., \& Ringle, C. M. (2016). Identifying and treating unobserved heterogeneity with FIMIXPLS. European Business Review, 28(2), 208-224.

Mosteanu, N. R., \& Faccia, A. (2020). Digital systems and new challenges of financial management FinTech, XBRL, Blockchain and Cryptocurrencies. Quality-Access to Success, 21(174), 159-166.

Ode, E., \& Ayavoo, R. (2020). The mediating role of knowledge application in the relationship between knowledge management practices and firm innovation. Journal of Innovation \& Knowledge, 5(3), 210-218.

Tohang, V., Limijaya, A. and Chitrahadi, M. (2020). An analysis of the impact of XBRL filings towards information asymmetry in Indonesia. International Conference on Information Management and Technology (ICIMTech) (pp. 330-335). IEEE.

Troshani, I., \& Doolin, B. (2007). Innovation diffusion: A stakeholder and social network view. European Journal of Innovation Management, $10(2), 176-200$.

Wang, D., Chen, Y., \& Xu, J. (2017). Knowledge management of web financial reporting in human-computer interactive perspective. EURASIA Journal of Mathematics, Science and Technology Education, 13(7), 3349-3373.

Wiseman, R. M., Cuevas-Rodríguez, G., \& Gomez-Mejia, L. R. (2012). Towards a social theory of agency. Journal of Management Studies, 49(1), 202-222.

Yoon, H., Zo, H., \& Ciganek, A. (2011). Does XBRL adoption reduce information asymmetry. Journal of Business Research, 64(2), $157-163$.

Zamroni, M., \& Aryani, Y. A. (2018). Initial effects of mandatory XBRL adoption across the Indonesia stock exchange's financial information environment. Jurnal Keuangan dan Perbankan, 22(2), 181-197.

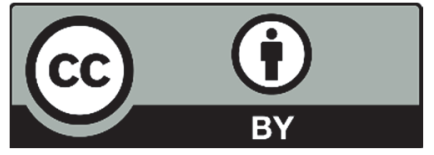

(C) 2021 by the authors; licensee Growing Science, Canada. This is an open access article distributed under the terms and conditions of the Creative Commons Attribution (CC-BY) license (http://creativecommons.org/licenses/by/4.0/). 